\title{
Repair bond strength of resin composite to three aged CAD/CAM blocks using different repair systems
}

\author{
Pinar Gul' ${ }^{*}$, Latife Altınok-Uygun² \\ 'Department of Restorative Dentistry, Faculty of Dentistry, Atatürk University, Erzurum, Turkey \\ ${ }^{2}$ Graduate Department of Restorative Dentistry, Faculty of Dentistry, Atatürk University, Erzurum, Turkey
}

\begin{abstract}
PURPOSE. The purpose of this study is to evaluate the repair bond strength of a nanohybrid resin composite to three CAD/CAM blocks using different intraoral ceramic repair systems. MATERIALS AND METHODS. Three CAD/CAM blocks (Lava Ultimate, Cerasmart, and Vitablocks Mark II) were selected for the study. Thirty-two specimens were fabricated from each block. Specimens were randomly divided into eight groups for the following different intraoral repair systems: Group 1: control group (no treatment); Group 2: 34.5\% phosphoric acid etching; Group 3: CoJet System; Group 4: Z-Prime Plus System; Group 5: GC Repair System; Group 6: Cimara System; Group 7: Porcelain Repair System; and Group 8: Clearfil Repair System. Then, nanohybrid resin composite (Tetric Evo Ceram) was packed onto treated blocks surfaces. The specimens were thermocycled before application of repair systems and after application of composite resin. After second thermal cycling, blocks were cut into bars $\left(1 \times 1 \times 12 \mathrm{~mm}^{3}\right)$ for microtensile bond strength tests. Data were analyzed using two-way ANOVA and Tukey's HSD test $(\alpha=.05)$. RESULTS. Cimara System, Porcelain Repair, and Clearfil Repair systems significantly increased the bond strength of nanohybrid resin composite to all CAD/CAM blocks when compared with the other tested repair systems $(P<.05)$. In terms of CAD/CAM blocks, the lowest values were observed in Vitablocks Mark II groups $(P<.05)$. CONCLUSION. All repair systems used in the study exhibited clinically acceptable bond strength and can be recommended for clinical use. [J Adv Prosthodont 2020;12:131-9]
\end{abstract}

KEYWORDS: CAD/CAM materials; Composite resin; Intraoral repair systems; Microtensile bond strenght

\section{INTRODUCTION}

Computer aided design and computer aided manufacturing (CAD/CAM) systems are becoming increasingly popular in dentistry, and indirect restorative materials can be developed

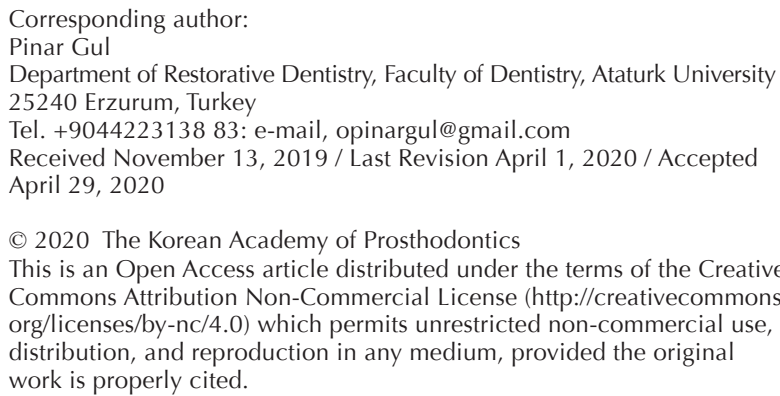

This work was supported by the Research Fund of Ataturk University (Project number: 2015/315). In addition, this study was presented in International Congress on Preventive Dentistry, 5-8 March 2018, Erzurum, Turkey. and blocks can be obtained in a pre-processed manner. Controlled fabrication of CAD/CAM blocks allows a homogenous and defect-free material to be obtained. ${ }^{1}$ The CAD/CAM materials can be categorized as ceramic and composites. $^{2}$ Vitablocks Mark II (Vita Zahnfabrik) is one of the ceramics commonly used today. Vitablocks Mark II consists of fine grained feldspathic ceramic compacted into a block. $^{3}$ Ceramic materials are superior to composite resins in terms of their aesthetic appearance, biocompatibility, durability, mechanical properties, and resistance to coloration. However, ceramics are structurally more brittle, i.e., more prone to breakage. On the other hand, the abrasion rate of composite resins is low, and finishing, polishing, and repair is easier. ${ }^{2,4,5}$

In addition to different types of ceramic blocks (feldspathic ceramic, reinforced glass ceramics, zirconia, etc.), new types of CAD/CAM blocks, called resin ceramic hybrid materials, have been developed. These materials combine the advantages such as color stability and durability 
of ceramics, and the low abrasion and high flexural properties of composite resins. ${ }^{4,6}$ The best known of these materials, Lava Ultimate (3M ESPE), is called resin nanoceramic and $80 \%$ of the material content consists of nanomers and nanocluster fillers. These nanomers consist of silica with a diameter of $20 \mathrm{~nm}$ and zirconia with a diameter of $4-11$ $\mathrm{nm}$. Cerasmart (GC), another resin nanoceramic, contains $71 \%$ silica and barium glass nanoparticles. ${ }^{2}$

Despite these advantages, breakages may occur in CAD/ CAM materials due to inadequate interconnection, inadequate occlusal alignment, internal stresses, parafunctional habits, and porosity in the material during production. Complete replacement of the restoration will not be a practical solution since it will increase preparation, resulting in loss of more healthy dental tissue. Therefore, direct repair application using composite resin offers a more appropriate treatment approach in terms of both preserving the healthy dental structure and achieving faster results at lower cost. ${ }^{7-9}$ Many processes are applied to ceramic surfaces in order to increase the function of ceramic restorations and to prolong their life. These are mainly acid etching (e.g. hydrofluoric acid (HF), acidified phosphate fluoride, and phosphoric acid (PA)), ${ }^{10-12}$ airborne particle abrasion with aluminum oxide, ${ }^{13}$ and airborne particle abrasion with silica-coated alumina. ${ }^{14-16}$ In addition to these, there are many commercial intraoral repair systems today. In the literature, studies on the effect of intraoral repair systems on the bond strength of composite resin to new CAD/CAM ceramics are limited.

For this reason, the aim of this study is to compare the bond strength of the nanocomposite resin to three CAD/ CAM blocks using different intraoral repair systems.

The hypotheses of the study are as follows:

1. There is no significant difference among the intraoral repair systems used for each CAD/CAM material

2. There is no significant difference in the bond strength of CAD/CAM materials in terms of each repair system.

\section{MATERIALS AND METHODS}

In the study, one feldspar ceramics (Vitablocks Mark II, VITA Zahnfabrik, Bad Säckingen, Germany) and two resin nanoceramics (Lava Ultimate, 3M ESPE, St. Paul, MN, USA and Cerasmart, GC Dental Products, Leuven, Belgium) CAD/ CAM blocks, and six different intraoral repair systems were used. The information on the materials used is given in Table 1.

A total of 32 samples with a dimension of $5 \times 5 \times 6 \mathrm{~mm}^{3}$ were obtained from each of the CAD/CAM blocks used in the study using an IsoMet Diamond Wafering Blades (Buehler, Lake Bluff, IL, USA) cutting device at low speed and under water cooling. The resulting ceramic blocks were aged first using a thermal cycle (MOD Dental, Ankara, Turkey) (between $5-55^{\circ} \mathrm{C}, 20$ seconds dwell time, 5000 cycles), and then samples were placed inside acrylic resin (Meliodent, Heraeus Kulzer GmbH, Germany). The sample surfaces were then standardized using a 600-grit silicon carbide $(\mathrm{SiC})$ sandpaper for 30 seconds and kept in distilled water for 24 hours. After these procedures, each block was divided into 8 subgroups for the application of different repair systems: Group 1: Control group; Group 2: roughening with 34.5\% phosphoric acid; Group 3: CoJet System (3M ESPE); Group 4: Z-Prime Plus (Bisco Inc); Group 5: GC Repair System (GC); Group 6: Cimara System (Voco); Group 7: Porcelain Repair System (South Jordan); and Group 8: Clearfil Repair System (Kuraray). The application procedures of the repair systems were made in accordance with the manufacturer's recommendation and are given in Table 2. In this study, aging was also performed before surface treatments in order to simulate the clinical situation and repair systems were applied to direct ceramic surfaces assuming a new surface.

After surface treatment, ceramic surfaces were restored using a nanohybrid composite resin (TetricEvoCeram, (A3), Ivoclar, Vivadent). The composite resin was polymerized in

Table 1. Description of the CAD/CAM blocks and composite resin used in the study

\begin{tabular}{|c|c|c|c|c|}
\hline Materials & Ceramic type & Composition & Manufacturer & Lot No. \\
\hline Lava Ultimate & Resin nano ceramic & $\begin{array}{l}\text { Bis-GMA, UDMA, TEGDMA, Bis-EMA; } \mathrm{SiO}_{2}(20 \mathrm{~nm}) \text {, } \\
\mathrm{ZrO}_{2}(4-11 \mathrm{~nm}) \text {, Aggregated } \mathrm{ZrO}_{2} / \mathrm{SiO}_{2} \text { cluster }\left(\mathrm{SiO}_{2}\right. \\
\left.=20 \mathrm{~nm}, \mathrm{ZrO}_{2}=4-11 \mathrm{~nm}\right)\end{array}$ & $\begin{array}{l}\text { 3M ESPE, St. Paul, } \\
\text { MN, USA }\end{array}$ & N574684 \\
\hline Cerasmart & Resin ceramic & $\begin{array}{l}\text { Bis-MEPP, UDMA, DMA, silica (20 nm), barium glass } \\
(300 \mathrm{~nm})\end{array}$ & $\begin{array}{l}\text { GC Dental Products, } \\
\text { Leuven, Belgium }\end{array}$ & 1601221 \\
\hline Vitablocks Mark II & Feldspar ceramic & Feldspathic crystalline particles in glassy matrix & $\begin{array}{l}\text { VITA Zahnfabrik, Bad } \\
\text { Säckingen, Germany }\end{array}$ & 49801 \\
\hline TetricEvoCeram & $\begin{array}{l}\text { Nanohybrid resin } \\
\text { composite }\end{array}$ & $\begin{array}{l}\text { Bis-GMA, Bis-EMA,UDMA ; Barium glass, ytterbium } \\
\text { trifluoride, mixed oxide prepolymer }\end{array}$ & $\begin{array}{l}\text { Ivoclar Vivadent, } \\
\text { Schaan, Liechtenstein }\end{array}$ & U23115 \\
\hline
\end{tabular}

Bis-GMA: bisphenol A diglycidylether methacrylate; Bis-MEPP: 2,2-Bis(4-methacryloxypolyethoxyphenyl)propane; UDMA:urethane dimethacrylate; TEGDMA: triethylene glycol dimethacrylate; Bis-EMA: ethoxylated bisphenol-A dimethacrylate; DMA: dimethacrylate. 
Table 2. Repair groups and application procedures used in the study

\begin{tabular}{|c|c|c|}
\hline $\begin{array}{l}\text { Repair systems and } \\
\text { manufacturers }\end{array}$ & Application procedures & Lot No. \\
\hline Control & $\begin{array}{l}\text { - No surface conditioning, } \\
\text { - Bonding and resin composite were applied }\end{array}$ & \\
\hline Acid Etching & $\begin{array}{l}\text { - Acid Etching ( } 34.5 \% \text { phosphoric acid (Vocoid, Voco) } \\
\text { - Bonding and resin composite were applied }\end{array}$ & \\
\hline $\begin{array}{l}\text { CoJet System } \\
\text { (3M ESPE) }\end{array}$ & $\begin{array}{l}\text { - Sandblasted by silicate-coated alumina particles with a diameter of } 30 \mathrm{~mm} \text { at a pressure of } \\
2.3 \text { bar and from a distance of } 10 \mathrm{~mm} \text {. } \\
\text { - Bonding and resin composite were applied }\end{array}$ & 649828 \\
\hline $\begin{array}{l}\text { Z-Prime Plus } \\
\text { (Bisco Inc.) }\end{array}$ & $\begin{array}{l}\text { - Porcelain Etchant }(9.5 \% \mathrm{HF}) \text { was applied for } 90 \mathrm{~s} \text {, rinsed and dried. } \\
\text { - Primer was applied and dried for } 5 \mathrm{~s} \text { in a compressed air system } \\
\text { - Resin composite was applied. }\end{array}$ & 1600006683 \\
\hline $\begin{array}{l}\text { GC Repair } \\
\text { (GC) }\end{array}$ & $\begin{array}{l}\text { - Ceramic Primer II was applied } \\
\text { - G-Premio Bond was applied for } 10 \mathrm{~s} \text {, dried for } 5 \mathrm{~s} \text { and cured for } 10 \mathrm{~s} . \\
\text { - Resin composite was applied. }\end{array}$ & $160616 \mathrm{~A}$ \\
\hline $\begin{array}{l}\text { Cimara System } \\
\text { (Voco) }\end{array}$ & $\begin{array}{l}\text { - Surface treated with Cimara grinding bur (10 strokes), removal of grind dust with a brush } \\
\text { - Coupling silane (leave for } 2 \text { min; no air drying) was applied } \\
\text { - Opaquer liquid ( } 20 \text { s photo-polymerization) was applied } \\
\text { - Resin composite was applied. }\end{array}$ & 1650234 \\
\hline $\begin{array}{l}\text { Porcelain Repair } \\
\text { (Ultradent } \\
\text { Product Inc.) }\end{array}$ & $\begin{array}{l}\text { - Ultradent porcelain etch ( } 9 \% \mathrm{HF} \text { ) was applied for } 90 \mathrm{~s} \text {; rinsed } 20 \mathrm{~s} \text {; dried } 5 \mathrm{~s} \\
\text { - Ultradent silane was applied for } 60 \mathrm{~s} \\
\text { - Peak Universal Bond was applied for } 15 \mathrm{~s} \text {; blow thin } 10 \mathrm{~s} \\
\text { - Resin composite was applied. }\end{array}$ & BCTSL \\
\hline $\begin{array}{l}\text { Clearfil Repair System } \\
\text { (Kuraray) }\end{array}$ & $\begin{array}{l}\text { - K-Etch gel (40\% phosphoric acid) was applied; rinsed and dried. } \\
\text { - Mixed } 1 \text { drop of SE Bond primer with } 1 \text { drop of Porcelain Bond activator; applied } 5 \mathrm{~s} \text { and dried. } \\
\text { - Applied SE Bond for } 15 \mathrm{~s} \text {; blow thin; light-curing } 10 \mathrm{~s} \\
\text { - Resin composite was applied. }\end{array}$ & 180185 \\
\hline
\end{tabular}

$2 \mathrm{~mm}$ layers using an Elipar Freelight II (3M/ESPE; light power 1,200 $\mathrm{mW} / \mathrm{cm}^{2}$ ) light device, at 20 seconds for each layer. Samples were left in distilled water for 24 hours for post polymerization. After restorative processes, samples were aged again with a thermal cycle (MOD Dental) (between $5-55^{\circ} \mathrm{C}, 20$ seconds dwell time, 5000 cycles).

After the second aging process, $1 \times 1 \times 12 \mathrm{~mm}^{3}$ barshaped samples were obtained using IsoMet Diamond Wafering Blades (Buehler, Lake Bluff, IL, USA). For the reliability of the data obtained, the bars in the center of each ceramic sample were included in the study $(n=20)$. To measure the bond strength between ceramic and composite, samples were mounted on a microtensile tester (Bisco Inc., Schaumburg, IL, USA) using adhesive (Zapit, Dental Ventures of America, Corona, CA, USA) and force was applied until the failure occurred at a rate of $1 \mathrm{~mm} / \mathrm{min}$. The bond strength (in $\mathrm{MPa}$ ) of each sample was calculated by dividing the applied load (in $\mathrm{N}$ ) by the surface area of the sample (in $\mathrm{mm}^{2}$ ).

SEM images were obtained to examine the changes that occurred after the repair systems were applied to the ceramic surfaces. A separate sample was prepared for each group to obtain SEM images (Fig. 1).

In addition, failure modes were determined under $40 \times$ magnification with a light microscope (Axiovert, Carl Zeiss, Oberkochen, Germany) and were classified as adhesive (failure in adhesive-ceramic interface), composite cohesive (failure within the composite resin), ceramic cohesive (failure within the ceramic), and mixed (both adhesive and cohesive failure).

The failure surfaces of the samples were also examined using a scanning electron microscope, Zeiss Sigma SEM (Zeiss Sigma VP, Carl Zeiss, Oberkochen, Germany). The surfaces of the dried samples were covered with gold palladium and SEM images were obtained at different magnifications.

The obtained data were analyzed using Statistical Package for the Social Sciences (SPSS) 18 (IBM, Chicago, IL, USA) statistical package program. Kolmogorov Smirnov and Shapiro-Wilk test were performed to determine whether the data were normally distributed. In addition, the control of variance homogenity was performed using Levene's test. The data were analyzed with two-way ANOVA and the Tukey post hoc test. Statistical significance level was taken as $\alpha=.05$. 


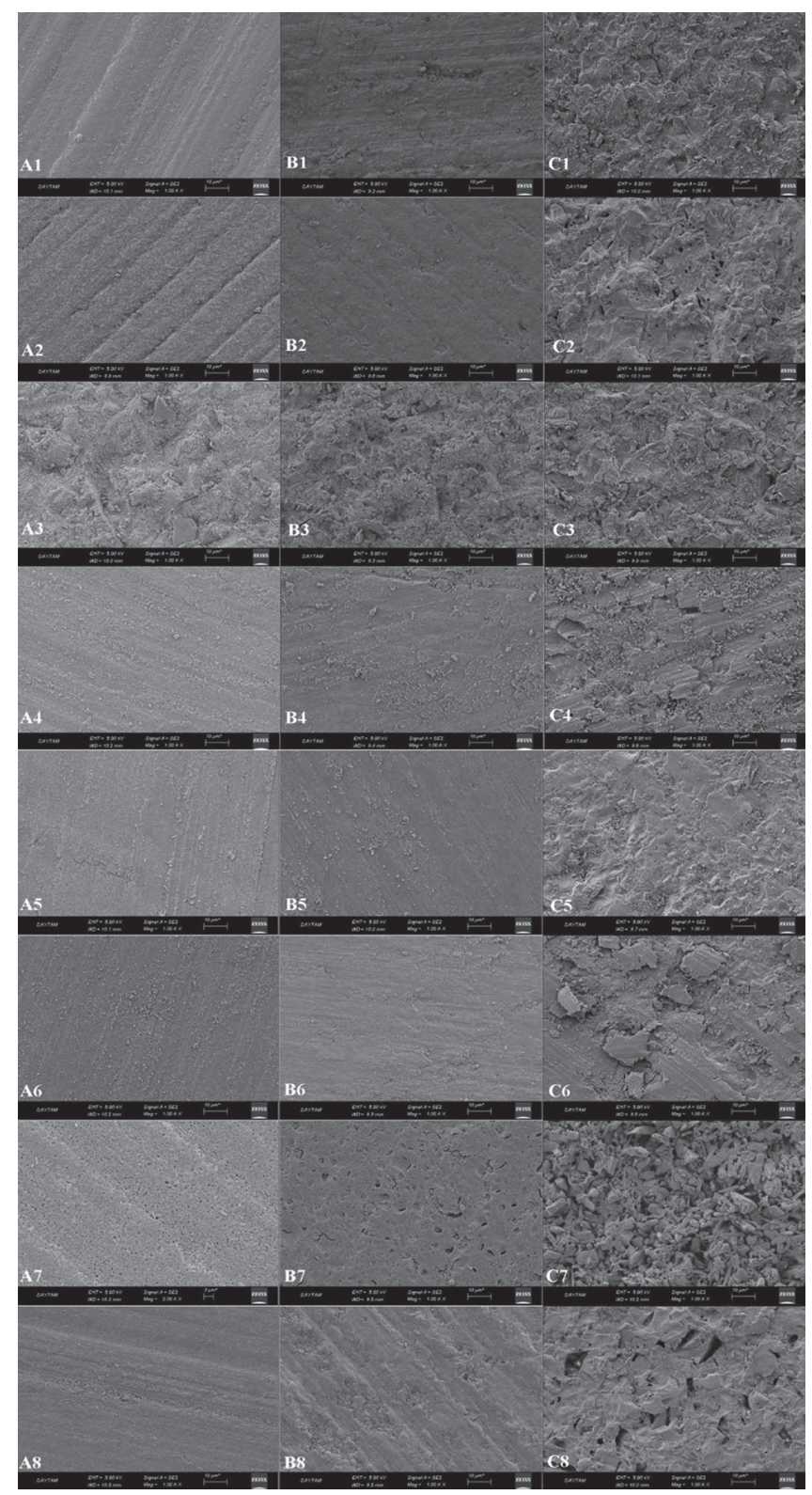

Fig. 1. SEM images of the samples. A: Cerasmart, B: Lava Ultimate, C: Vitablocks Mark II, 1: Control, 2: Acid Etching, 3: CoJet System, 4: Z-Prime Plus, 5: GC Repair, 6: Cimara System, 7: Porcelain Repair, 8: Clearfil Repair $(1000 \times$ magnification $)$.

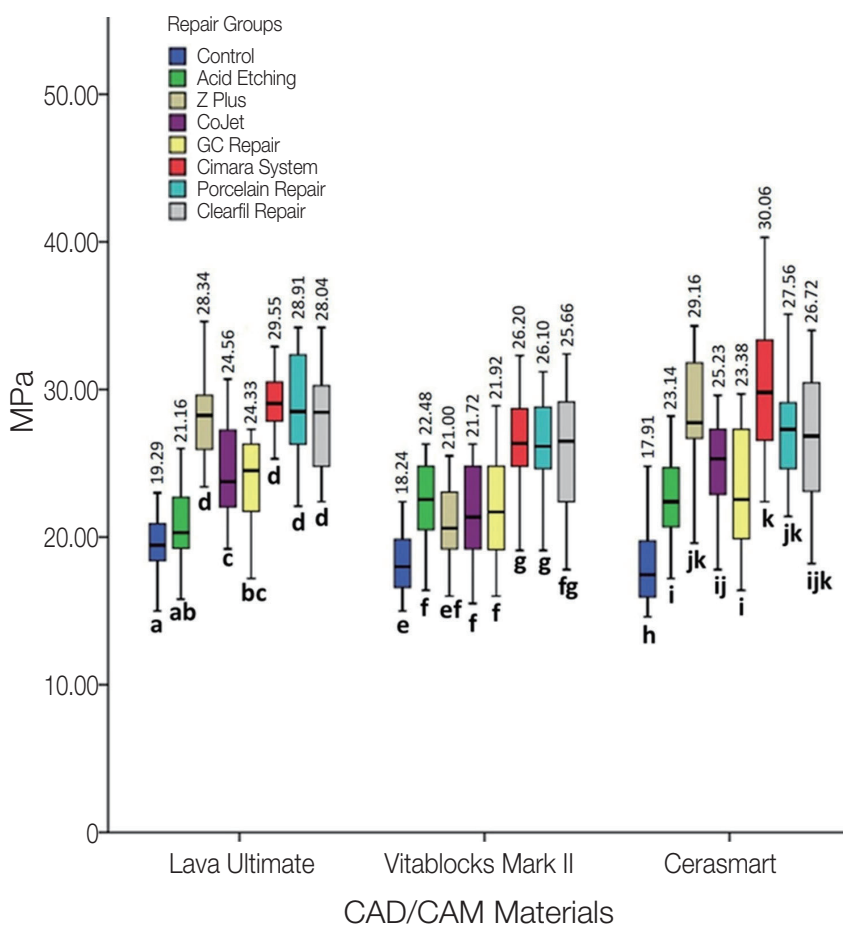

Fig. 2. Mean values and statistical analysis results of the $\mu \mathrm{TBS}$ (MPa) of CAD/CAM block/resin composite with different repair treatments. ${ }^{*} P<.05$. Different letters indicate significant differences.

\section{RESULTS}

The bond strength values (in $\mathrm{MPa}$ ) obtained as a result of repairing three different CAD/CAM materials with different repair systems and the statistical comparison results are given in Fig. 2 and Table 3. A statistically significant difference was found among the groups as a result of the twoway ANOVA test used for comparison of repair systems $(P$ $<$.001) (Table 3). According to the Tukey HSD test results, the lowest bonding values were obtained in the control groups. It was determined that all repair systems applied to

Table 3. Results of two-way ANOVA

\begin{tabular}{|c|c|c|c|c|c|}
\hline Source & SS & df & MS & $\mathrm{F}$ & $P$ \\
\hline Intercept & 290693.320 & 1 & 290693.320 & 21981.466 & $<.001$ \\
\hline Block materials & 691.662 & 2 & 345.831 & 26.151 & $<.001$ \\
\hline Repair groups & 4637.526 & 7 & 662.504 & 50.097 & $<.001$ \\
\hline Materials * Repair groups & 687.052 & 14 & 49.075 & 3.711 & $<.001$ \\
\hline Error & 6030.360 & 456 & 13.224 & & \\
\hline Total & 302739.920 & 480 & & & \\
\hline Corrected total & 12046.600 & 479 & & & \\
\hline
\end{tabular}

SS: sum of squares, MS: mean of squares, $P<.05$ significant 


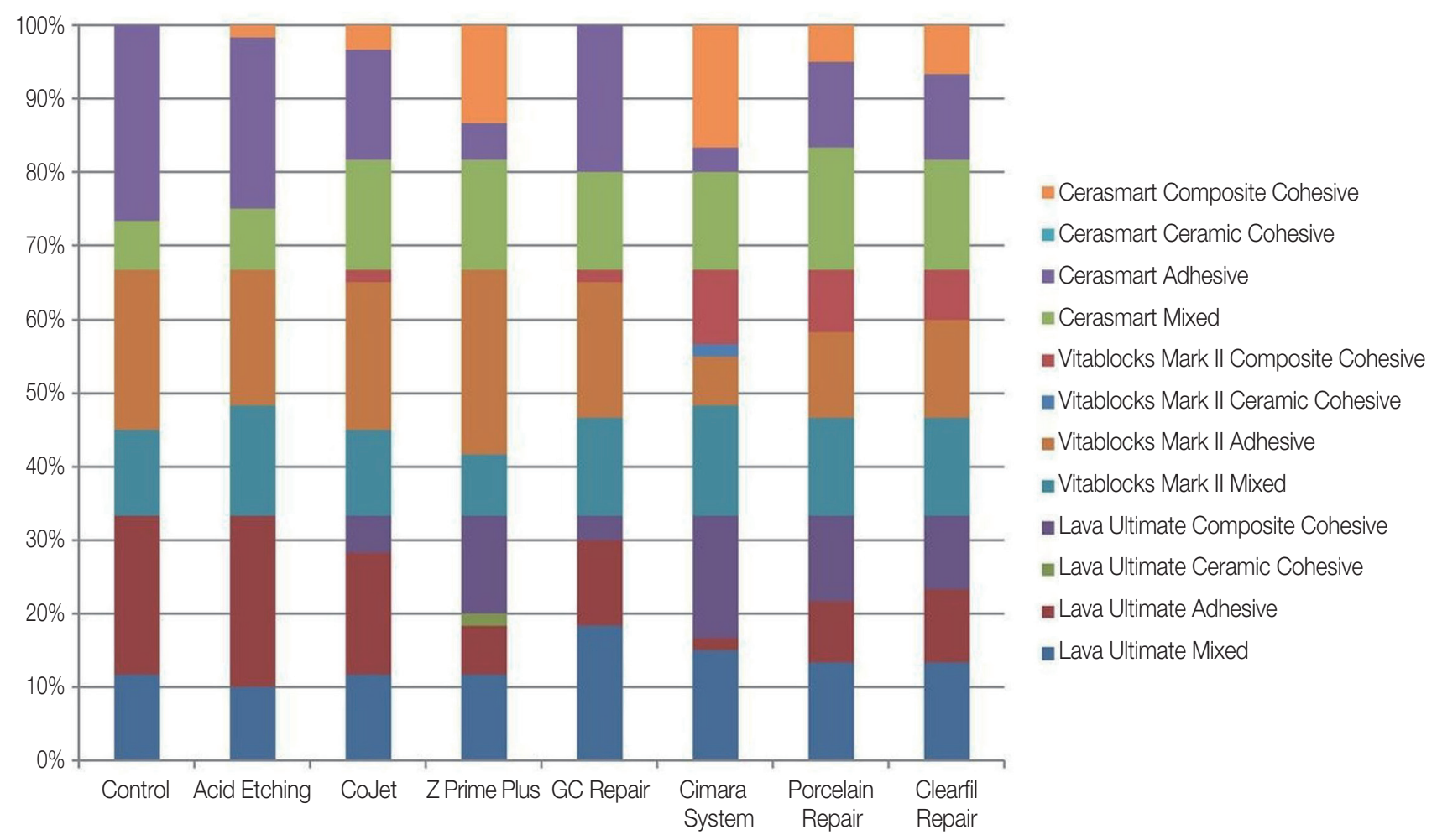

Fig. 3. Failure mode distributions (\%) of test groups.

the ceramic surfaces increased the bonding values significantly compared to the control group $(P<.05)$ (Fig. 2). However, in all of the blocks, significantly higher values were obtained in the Cimara System, Porcelain Repair, and Clearfil Repair systems than the other groups $(P<.05)$. The values obtained from the $Z$ Prime Plus group for resin nanoceramics were similarly high to those obtained from Porcelain Repair and Clearfil Repair systems $(P>.05)$.

Based on the results of two-way ANOVA test for comparison of CAD/CAM materials for repair systems, significant difference was found among the materials $(P<.001)$ (Table 3). According to Tukey HSD test results for the groups that showed a significant difference, lower bonding values were obtained in Vitablocks Mark II compared to other blocks. No significant difference was found between Lava Ultimate and Cerasmart materials $(P>.05)$.

In this study, the values of failure modes that occurred in the samples are given in Fig. 3 as percentages (\%). All three blocks generally had adhesive and mixed failures, and most adhesive failures were seen in Vitablocks Mark II (20 $75 \%$ ) material. Ceramic cohesive failure only occurred in one sample in the Lava Ultimate-Z Prime Plus and Vitablocks Mark II-Cimara System group.

SEM images of each failure mode are shown in Fig. 4. In addition, SEM images of the changes occurring on the surfaces of all the ceramics after the repair procedures are shown in Fig. 1. In the SEM study, it was observed that the Vitablocks Mark II material showed a structural difference

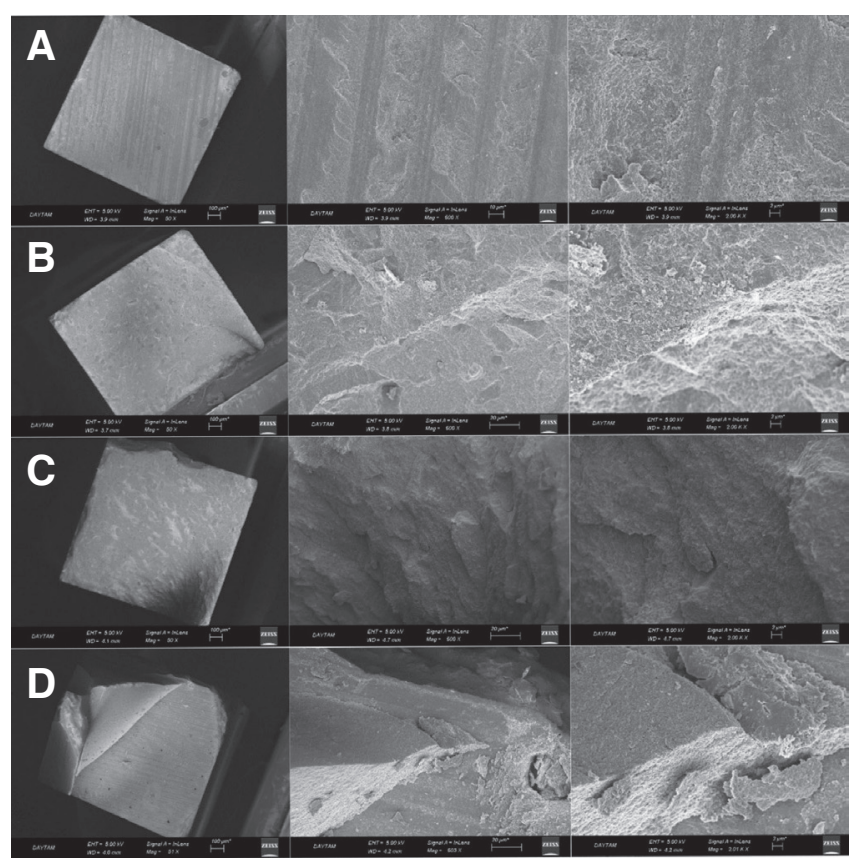

Fig. 4. SEM images of each failure mode. (A) Adhesive failure $(50 \times, 600 \times, 2000 \times)$ (Vitablocks Mark II), (B) Composite cohesive failure $(50 \times, 600 \times, 2000 \times)$

(Cerasmart), (C) Ceramic cohesive failure (50x, 600x, 2000x) (Lava Ultimate), (D) Mixed cohesive failure (50x, 600×, 2000×) (Lava Ultimate). 
compared to the other resin ceramic materials. Additionally, repair systems were found to cause more roughness rather than the control groups (Fig. 1).

\section{DISCUSSION}

In this study, microtensile bond strength ( $\mu$ TBS) of nanocomposite resin to three CAD/CAM blocks was investigated using different intraoral repair systems. Along with the continuous improvement of their properties, composite resins are frequently used in the repair of ceramic restorations. ${ }^{17}$ Intraoral repair applications are a more practical application for clinical use due to their minimally invasive approach and lower cost. Although many products are available on the market as intraoral repair systems, the system that meets all expectations of clinicians is not yet available. In the present study, a nanocomposite resin which is frequently used in the repair of CAD/CAM materials was used.

There are many tests that can be used to measure the bond strength, such as shear, micro shear, tensile, micro tensile bond strength and pull-out tests, but the most commonly used tests are micro shear and micro tensile bond strength tests. The advantage of the micro-tensile bond strength test ( $\mu \mathrm{TBS})$ is that a small amount of material can be used and even very small stress distributions can be investigated. The advantage of the micro shear bond strength test is that it is easy to apply, but its reliability is debatable because the stress distribution in the bond area is not uniform. ${ }^{18,19}$ In contrast, the $\mu$ TBS test exhibits a more uniform stress distribution during loading, which leads to less failure rates and higher bonding values. ${ }^{19-21}$ For this reason, the $\mu$ TBS test was applied to the samples in the present study and only the bars in the centers of the samples were included in the study in order to make the data more reliable.

Restorations are exposed to different temperatures in oral cavity. Although the temperature of the oral cavity is normally $35-37^{\circ} \mathrm{C}$, these values vary due to food and hot or cold beverages. ${ }^{22-24}$ These temperature changes will cause mechanical stresses and cracking and their spreading in resin-containing materials, particularly due to differences in the thermal expansion of the filler and resin matrix.,3,25 As a result, this will cause aging and clinical failure in the restorative material. In in vitro studies, thermal cycling has been performed to mimic intraoral temperature changes. The ceramic samples obtained in the present study were subjected to thermal cycling twice, 5000 cycles before the repair systems were applied and 5000 cycles after being repaired with the composite resin (10000 cycles in total). Clinically, aging will directly affect the mechanical, chemical, and physical properties of the material and therefore its repairability. ${ }^{9,27}$ In the literature, the number of cycles varies between studies, and 5000 cycles have been reported to correspond to a period of 6 months of in vivo aging. ${ }^{28}$ While most studies perform 5000 or 10000 cycles, there are also studies with less number of cycles. ${ }^{15,29}$ Blackburn et al. ${ }^{3}$ reported that thermal cycling at 5000 and 10000 cycles results in similar aging of the samples. Looking at the studies in the literature on the effect of thermal cycling application on the bond strength of restorative materials, while the bonding values obtained in the studies differ due to the reasons such as the type of restorative materials, the number of thermal cycles, the surface treatment of the samples, and the bond strength method applied, thermal cycling has generally been reported to reduce bond strength. ${ }^{6,30,31}$ Clinically, when considered in terms of ideal bonding value, it has been reported that the bonding value should be at least $20 \mathrm{MPa}$ depending on the composite resin used and the repair method. ${ }^{6,32}$ Looking at the results obtained in the present study, it was found that all the intraoral repair systems increased the bond strength significantly compared to the control group despite an aging procedure of 10000 cycles $(1$ year) $(P<.05)$ (Fig. 2). In this case, first hypothesis was rejected. In all groups except the control group, the minimum $\mu$ TBS was measured as 21.00 $\pm 2.87 \mathrm{MPa}$ and the maximum $\mu$ TBS was measured as 30.06 $\pm 4.54 \mathrm{MPa}$ (Fig. 2).

Today, the adhesion principles are generally based on the combination of physical and chemical bonding. In repair processes, the first stage is to prepare the surface to which the repair systems will be applied, followed by the application of agents to allow chemical bonding. ${ }^{33}$ In this respect, studies in the literature are mostly concerned with surface treatments but studies comparing commercial intraoral repair systems are limited. ${ }^{10-16}$ Phosphoric acid can be used at different concentrations in the surface roughening process because of its ease of application, low cost and being more acceptable by the patients. There are studies in the literature reporting the positive effects of the use of phosphoric acid on bond strength. ${ }^{34-36}$ In the present study, in addition to intraoral repair system, phosphoric acid application alone was also applied to the ceramic surfaces (Group 2). Although not as much as the other groups, phosphoric acid group showed a significant increase in bond strength compared to the control group $(P<.05)$ (Fig. 2). Subaşı and Inan investigated the effect of two repair systems using acid roughening on the ceramics, Clearfil Repair (40\% phosphoric acid) and Ultradent Repair (9\% HF), and reported that $\mathrm{HF}$ acid was more successful in roughening. ${ }^{37}$

In this study, the standardization of the ceramic surfaces was initially performed using 600 grit silicon carbide (SiC) sandpaper, and no bur treatment was done. Erdemir et al. ${ }^{29}$ reported that high roughness values were obtained with a diamond bur, but the application did not increase the bond strength. Researchers have reported that bur treatment results in roughening on a macro scale, micromechanical bonding is important for bond strength, and therefore the geometric character of the roughening is more important.

Duzyol et al. ${ }^{17}$ applied 5\% HF acid, sanblasting, and CoJet systems after bur roughening of different types of $\mathrm{CAD} / \mathrm{CAM}$ ceramic surfaces, and then reported that these surface treatments did not increase the bond strength of feldspar and nanoceramics. Erdemir et al. ${ }^{29}$ have argued that HF acid and CoJet systems together provide the best bond- 
ing. Melo et al. ${ }^{38}$ and Frankenberger et al..$^{39}$ reported that in the ceramic samples to which the CoJet system was applied, similar bond strengths with HF acid application were obtained. Contrary to these findings, Rüttermann et al..$^{40}$ found that the CoJet system provided better results on ceramic surfaces than HF acid. Rathke et al. ${ }^{41}$ found that silane application did not increase the bonding of the composite resin following CoJet application, but contrary to this, many studies have reported more successful results with silane application after CoJet application compared to phosphoric acid and adhesive application. ${ }^{36,42-44}$ As can be seen from these studies, the results vary. This is because the bond strength of the composite resin to the ceramic material is affected by many factors such as the type of composite resin used, the type of ceramic, and the application method of the repair system. ${ }^{15}$ In this study, bond strength of the CoJet system was found to be significantly higher in all ceramics compared to the control group $(P<.05)$ (Fig. 2). Despite the positive effects of the Cojet system on bonding, there are disadvantages such as contamination of the ceramic surface by sand particles, risk of causing health problems, and additional cost of the application device. ${ }^{33,45}$ Furthermore, sandblasting can cause large volume losses on ceramic surfaces, which is why its use on materials such as feldspar ceramics is risky. ${ }^{15}$ The repair systems in the market are mainly based on the use of silane to achieve chemical bonding to microretentive surfaces obtained by sandblasting or acid application. ${ }^{46}$ Silane acts as a chemical bonding agent between organic and inorganic surfaces. Silane is a bifunctional monomer containing the methacrylate group that copolymerizes with the organic matrix of the composite and the silanol group that reacts with the ceramic surfaces. ${ }^{33}$ However, it has been reported in the literature that the bonding effect of silane cannot be optimal without pretreatment of ceramic surfaces. ${ }^{15,47}$

All intraoral repair systems used in the present study were applied according to the manufacturer's instructions. It was found that the bond strength for all repair systems was significantly higher than the control group $(P<.05)$ (Fig. 2). In the SEM images, the surface properties of the samples were found to vary according to the control groups (Fig. 1). According to the results of the failure mode analysis, the highest rate of adhesive failure was observed in the control groups (Fig. 3). However, Cimara System, Porcelain Repair, and Clearfil Repair systems showed significantly higher bond strength in all ceramics $(P<.05)$ (Fig. 2). In these three systems, the rate of mixed failure was found to be more than the rate of adhesive failure (Fig. 3). In addition, the bond strength of Z Prime Plus group in resin nanoceramic blocks was similar to these systems $(P>.05)$. These systems are based on acid application and silane use. There are similar studies in the literature on the positive effect of these systems on bond strength. ${ }^{15,33,42,48,49}$

In this study, when the success of repair systems were compared in terms of ceramic systems, lower bond strength values were generally obtained in feldspathic ceramics than in nano ceramics $(P<.05)$ (Fig. 2$)$. This may be due to the structural similarity of used repair composite with the resin nanoceramics. In this case, second hypothesis was also rejected. Failure mode analysis results also support this view. The highest rate of adhesive failure was seen in feldspar ceramic groups (Fig. 3). In addition, the surface properties of the resin nano ceramics were similar in the SEM images (Fig. 1).

Feldspathic ceramics have been strengthened with alumina addition $(50 \%)$ to their contents. However, it has been reported that such ceramics cannot be roughened by acid, and that achieving sufficient bonding with silane and adhesives alone is questionable. ${ }^{33}$ Zaghloul et al. ${ }^{27}$ reported that for all repair systems except HF acid and silane application, the bonding rates obtained by repair of CAD/CAM composite blocks using composite resin were higher than those of CAD/CAM ceramic blocks. This was based on the elastic modulus difference between the two materials. This is because resiliency of composite polymer material can withstand stress; whereas ceramic materials are prone to fracture even at lower values due to their fragile nature. The other reason why feldspar ceramics showed lower bonding values than resin nano ceramics in the present study may also be due to this fact.

\section{CONCLUSION}

Within the limitations of this study, all repair systems used in the study exhibited clinically acceptable bond strength and can be recommended for clinical use. In addition, for all ceramics used in the study, Cimara System, Porcelain Repair, and Clearfil Repair showed significantly higher bond strength compared to other systems. The success of CAD/ CAM blocks depends on the ceramic type. Resin nano ceramics are more successful in intraoral repair applications.

\section{ORCID}

Pinar Gul https:/ / orcid.org/0000-0003-3714-4991

Latife Altınok-Uygun bttps:// orcid.org/0000-0003-2593-171X

\section{REFERENCES}

1. Wendler M, Belli R, Petschelt A, Mevec D, Harrer W, Lube T, Danzer R, Lohbauer U. Chairside CAD/CAM materials. Part 2: Flexural strength testing. Dent Mater 2017;33:99-109.

2. Kurtulmus-Yilmaz S, Cengiz E, Ongun S, Karakaya I. The effect of surface treatments on the mechanical and optical behaviors of CAD/CAM restorative materials. J Prosthodont 2019;28:e496-503.

3. Blackburn C, Rask H, Awada A. Mechanical properties of resin-ceramic CAD-CAM materials after accelerated aging. J Prosthet Dent 2018;119:954-8.

4. Coldea A, Swain MV, Thiel N. Mechanical properties of polymer-infiltrated-ceramic-network materials. Dent Mater 2013; 29:419-26.

5. Zhang Y, Sailer I, Lawn BR. Fatigue of dental ceramics. J Dent 2013;41:1135-47. 
6. Güngör MB, Nemli SK, Bal BT, Ünver S, Doğan A. Effect of surface treatments on shear bond strength of resin composite bonded to CAD/CAM resin-ceramic hybrid materials. J Adv Prosthodont 2016;8:259-66.

7. Rekow ED, Silva NR, Coelho PG, Zhang Y, Guess P, Thompson VP. Performance of dental ceramics: challenges for improvements. J Dent Res 2011;90:937-52.

8. Reston EG, Filho SC, Arossi G, Cogo RB, Rocha Cdos S, Closs LQ. Repairing ceramic restorations: final solution or alternative procedure? Oper Dent 2008;33:461-6.

9. Üstün Ö, Büyükhatipoğlu IK, Seçilmiş A. Shear bond strength of repair systems to new CAD/CAM restorative materials. J Prosthodont 2018;27:748-54.

10. Filho AM, Vieira LC, Araújo E, Monteiro Júnior S. Effect of different ceramic surface treatments on resin microtensile bond strength. J Prosthodont 2004;13:28-35.

11. Kussano CM, Bonfante G, Batista JG, Pinto JH. Evaluation of shear bond strength of composite to porcelain according to surface treatment. Braz Dent J 2003;14:132-5.

12. Tylka DF, Stewart GP. Comparison of acidulated phosphate fluoride gel and hydrofluoric acid etchants for porcelain-composite repair. J Prosthet Dent 1994;72:121-7.

13. Kupiec KA, Wuertz KM, Barkmeier WW, Wilwerding TM. Evaluation of porcelain surface treatments and agents for composite-to-porcelain repair. J Prosthet Dent 1996;76:11924.

14. Blum IR, Nikolinakos N, Lynch CD, Wilson NH, Millar BJ, Jagger DC. An in vitro comparison of four intra-oral ceramic repair systems. J Dent 2012;40:906-12.

15. Elsaka SE. Repair bond strength of resin composite to a novel CAD/CAM hybrid ceramic using different repair systems. Dent Mater J 2015;34:161-7.

16. Ozcan M. The use of chairside silica coating for different dental applications: a clinical report. J Prosthet Dent 2002;87: 469-72.

17. Duzyol M, Sagsoz O, Polat Sagsoz N, Akgul N, Yildiz M. The effect of surface treatments on the bond strength between CAD/CAM blocks and composite resin. J Prosthodont 2016; 25:466-71.

18. Braga RR, Meira JB, Boaro LC, Xavier TA. Adhesion to tooth structure: a critical review of "macro" test methods. Dent Mater 2010;26:e38-49.

19. Papia E, Larsson C, du Toit M, Vult von Steyern P. Bonding between oxide ceramics and adhesive cement systems: a systematic review. J Biomed Mater Res B Appl Biomater 2014;102:395-413.

20. Park JH, Choi YS. Microtensile bond strength and micromorphologic analysis of surface-treated resin nanoceramics. J Adv Prosthodont 2016;8:275-84.

21. Pashley DH, Carvalho RM, Sano H, Nakajima M, Yoshiyama M, Shono Y, Fernandes CA, Tay F. The microtensile bond test: a review. J Adhes Dent 1999;1:299-309.

22. Morresi AL, D’Amario M, Capogreco M, Gatto R, Marzo G, D'Arcangelo C, Monaco A. Thermal cycling for restorative materials: does a standardized protocol exist in laboratory testing? A literature review. J Mech Behav Biomed Mater 2014;29:295-308.
23. Palmer DS, Barco MT, Billy EJ. Temperature extremes produced orally by hot and cold liquids. J Prosthet Dent 1992;67: 325-7.

24. Spierings TA, Peters MC, Bosman F, Plasschaert AJ. Verification of theoretical modeling of heat transmission in teeth by in vivo experiments. J Dent Res 1987;66:1336-9.

25. Gale MS, Darvell BW. Thermal cycling procedures for laboratory testing of dental restorations. J Dent 1999;27:89-99.

26. Çelik Köycü B, İmirzalıŏlu P. Heat transfer and thermal stress analysis of a mandibular molar tooth restored by different indirect restorations using a three-dimensional finite element method. J Prosthodont 2017;26:460-73.

27. Zaghloul H, Elkassas DW, Haridy MF. Effect of incorporation of silane in the bonding agent on the repair potential of machinable esthetic blocks. Eur J Dent 2014;8:44-52.

28. Subaş 1 MG, Alp G. Repair bond strengths of non-aged and aged resin nanoceramics. J Adv Prosthodont 2017;9:364-70.

29. Erdemir U, Sancakli HS, Sancakli E, Eren MM, Özel S, Yucel T, Yildiz E. Shear bond strength of a new self-adhering flowable composite resin for lithium disilicate-reinforced CAD/ CAM ceramic material. J Adv Prosthodont 2014;6:434-43.

30. Baur V, Ilie N. Repair of dental resin-based composites. Clin Oral Investig 2013;17:601-8.

31. Özel Bektas Ö, Eren D, Herguner Siso S, Akin GE. Effect of thermocycling on the bond strength of composite resin to bur and laser treated composite resin. Lasers Med Sci 2012; 27:723-8.

32. Wiegand A, Stucki L, Hoffmann R, Attin T, Stawarczyk B. Repairability of CAD/CAM high-density PMMA- and composite-based polymers. Clin Oral Investig 2015;19:2007-13.

33. Ozcan M, Valandro LF, Amaral R, Leite F, Bottino MA. Bond strength durability of a resin composite on a reinforced ceramic using various repair systems. Dent Mater 2009;25:147783.

34. Dos Santos VH, Griza S, de Moraes RR, Faria-E-Silva AL. Bond strength of self-adhesive resin cements to composite submitted to different surface pretreatments. Restor Dent Endod 2014;39:12-6.

35. Kirmali O, Barutcugil C, Harorli O, Kapdan A, Er K. Resin cement to indirect composite resin bonding: effect of various surface treatments. Scanning 2015;37:89-94.

36. Ozcan M, Barbosa SH, Melo RM, Galhano GA, Bottino MA. Effect of surface conditioning methods on the microtensile bond strength of resin composite to composite after aging conditions. Dent Mater 2007;23:1276-82.

37. Subaşi G, Inan O. Shear bond strength of three porcelain repair systems on porcelain in dry and aged conditions. Dentistry 2012;2:1-7.

38. de Melo RM, Valandro LF, Bottino MA. Microtensile bond strength of a repair composite to leucite-reinforced feldspathic ceramic. Braz Dent J 2007;18:314-9.

39. Frankenberger R, Krämer N, Sindel J. Repair strength of etched vs silica-coated metal-ceramic and all-ceramic restorations. Oper Dent 2000;25:209-15.

40. Rüttermann S, Fries L, Raab WH, Janda R. The effect of different bonding techniques on ceramic/resin shear bond strength. J Adhes Dent 2008;10:197-203. 
41. Rathke A, Tymina Y, Haller B. Effect of different surface treatments on the composite-composite repair bond strength. Clin Oral Investig 2009;13:317-23.

42. Hisamatsu N, Atsuta M, Matsumura H. Effect of silane primers and unfilled resin bonding agents on repair bond strength of a prosthodontic microfilled composite. J Oral Rehabil 2002;29:644-8.

43. Swift EJ Jr, Cloe BC, Boyer DB. Effect of a silane coupling agent on composite repair strengths. Am J Dent 1994;7:2002.

44. Tinastepe N, Turkes E, Kazazoglu E. Comparative approach to analyse the effects of different surface treatments on CAD/CAM resin nanoceramics-resin composite repair bond strength. Biotechnol Biotec Eq 2018;32:142-9.

45. Ozcan M, Vallittu PK. Effect of surface conditioning methods on the bond strength of luting cement to ceramics. Dent Mater 2004;19:725-31.

46. Carrabba M, Vichi A, Louca C, Ferrari M. Comparison of traditional and simplified methods for repairing CAD/CAM feldspathic ceramics. J Adv Prosthodont 2017;9:257-64.

47. Shahverdi S, Canay S, Sahin E, Bilge A. Effects of different surface treatment methods on the bond strength of composite resin to porcelain. J Oral Rehabil 1998;25:699-705.

48. Kim SM, Yoon JY, Lee MH, Oh NS. The effect of resin cements and primer on retentive force of zirconia copings bonded to zirconia abutments with insufficient retention. J Adv Prosthodont 2013;5:198-203.

49. Kirmali O, Kapdan A, Harorli OT, Barutcugil C, Ozarslan MM. Efficacy of ceramic repair material on the bond strength of composite resin to zirconia ceramic. Acta Odontol Scand 2015;73:28-32. 